\title{
Isolated eye-lid ptosis as initial manifestation of pediatric Behcet's Disease (BD)
}

\author{
M Alessio*, R Indaco, R Carlomagno and A Romano
}

Address: Department of Pediatrics Federico II University, Naples, Italy

* Corresponding author

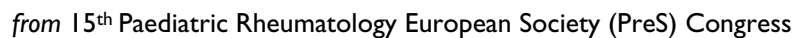

London, UK. 14-17 September 2008

Published: 15 September 2008

Pediatric Rheumatology 2008, 6(Suppl I):P269 doi:10.II86/I546-0096-6-SI-P269

This abstract is available from: http://www.ped-rheum.com/content/6/SI/P269

(C) 2008 Alessio et al; licensee BioMed Central Ltd.

$\mathrm{BD}$ is a chronic, multisystem inflammatory disorder. Neuro-Behçet's disease could be the first sign of the disease, but is infrequently described in childhood [1]. Isolated cranial nerve involvement has been reported [2], but to the best of our knowledge this is the first report of isolated eye-lid ptosis, without reduction of ocular motility, at onset of pediatric $\mathrm{BD}$.

PD is an 11-year-old girl first admitted in our hospital with bilateral eye-lid ptosis and headache. She was in good health until one month before the admission; she presented ptosis of eye-lids which was more evident on the left side, without other pathological findings. The normality of the EEG, cranial and midollar MRI, angio MRI, progstigmine test and laboratory tests excluded brain tumors, demyelinating diseases and miastenia gravis. She improved without therapy. After 4 months she experienced folliculitis of the trunk and wrist arthritis. After 8 months she suffered from oral and vaginal aphtosis. BD was diagnosed on the basis of these clinical signs according to the International Criteria. EEG, cerebral SPECT and an ocular examination were performed with normal results; HLA was B51 positive and this is an indicator of BD. Prednisone therapy was started $(1 \mathrm{mg} / \mathrm{Kg} /$ day $)$ and symptoms greatly improved within 6 months.

We can hypothesize that a bilateral occlusion of little blood vessels, caused by an inflammatory process provokes a temporary dysfunction of neurons that control each of the eyelid elevator muscles.
In conclusion $\mathrm{BD}$ is an important differential diagnosis for the partial oculomotor palsy as present case.

\section{References}

I. Kone-Paute I, Chabrol B, Riss JM, Mancini J, Raybaud C, Garnier JM: Neurologic onset of Behçet's disease: a diagnostic enigma in childhood. J Child Neurol 1997, I 2:237-4|.

2. Aydin MD, Aydin N: A neuro-Behçet's lesion in oculomotor nerve nucleus. Acta Neurol Scand 2003, 108:139-40. 